\title{
Las Mujeres-Ganso de Crossbones Graveyard
}

Women-Geese of Crossbones Graveyard

Estíbaliz Pérez Asperilla

epasperilla@ucm.es

Universidad Complutense de Madrid - España

Recibido: 27-02-2017

Aceptado: 04-06-2017

\section{Resumen}

Este artículo se enmarca dentro de la investigación Los cinco sentidos del Distrito Cultural en Londres, la cual forma parte del Proyecto de Excelencia 2016-2018 Distritos Culturales: imágenes e imaginarios en los procesos de revitalización de espacios urbanos. Escogiendo Bankside como punto de partida, para dicha investigación se han analizado diferentes emplazamientos como Crossbones Graveyard -antiguo cementerio donde se encuentran enterradas muchas de las mujeres que ejercieron la prostitución en el Distrito entre los siglos XII y XVII-. Desde su descubrimiento en la década de los 90 se han llevado a cabo numerosas acciones gracias a las cuales se ha conseguido no sólo su conservación, sino difundir la verdadera historia de las "Winchester Geese".

Palabras clave: Crossbones, ganso, mujer, espiritualidad, sexualidad.

\begin{abstract}
This paper is part of the research Five senses of London Cultural District, which is part of the Excellence Project 2016-2018 Cultural Districts: images and imaginaries in the processes of revitalization of urban spaces. Choosing Bankside as a starting point, for this research different sites have been analysed such as Crossbones Graveyard -which is an old graveyard where many of the women who practiced prostitution in the District between the twelfth and seventeenth centuries were buried. Since its discovery in the 90's, many actions have been carried out, which have not only achieved the goal of preserving the place, but also spread the truth of "Winchester Geese's" story.
\end{abstract}

Key words: Crossbones, goose, woman, spirituality, sexuality. 


\section{Introducción}

Considerado originariamente como el barrio rojo de Londres, Bankside -ubicado dentro del municipio Southwark - se caracterizaba por ser un enclave donde el pecado, la noche, el crimen y lo prohibido tenían siempre cabida. La zona denominada como la City de Londres consiguió deshacerse de burdeles y teatros trasladándolos en su mayor parte al área conocida como the Liberty of the Clink -o simplemente Liberty- consiguiendo así que los burdeles tuvieran su máximo apogeo en Bankside alrededor del siglo XV puesto que pasó de albergar siete de ellos en 1381 a dieciocho en 1506 (Reilly y Marshall, 2001). "The City of London always viewed Southwark with suspicion. Although it recognised the town as a vibrant, active and productive place, and so a potential source of income, it disliked having such a large, autonomous and unpredictable neighbor on its doorstep"l (Reilly y Marshall, 2001: 18).

Desde el siglo XII hasta el siglo XVII esta zona estuvo bajo el control de los Obispos de Winchester quienes residían en Winchester Palace (fig. 1)-localizado entre la iglesia (actualmente Southwark Cathedral) y Clink Prision (figs. 2 y 3)-. Las mujeres que ejercían la prostitución en los burdeles eran conocidas como las "Winchester Geese"2, ya que pagaban una serie de tasas al Obispo para poder así ejercer su trabajo (Harris, 2010). En 1504 se intentó llevar a cabo la clausura de los burdeles, puesto que se temía por la expansión de la sífilis, pero esta prohibición sólo duró un año hasta que en 1546 fueron finalmente eliminados. Sin embargo, no lograron acabar con la prostitución -debido a que muchas de las mujeres optaron por ir a las tabernas- ni tampoco con los burdeles porque años más tarde éstos consiguieron normalizar de nuevo su negocio (Brandon y Brooke, 2011).

Figuras 1- 3. Winchester Palace, Southwark Cathedral y Clink Prision Museum
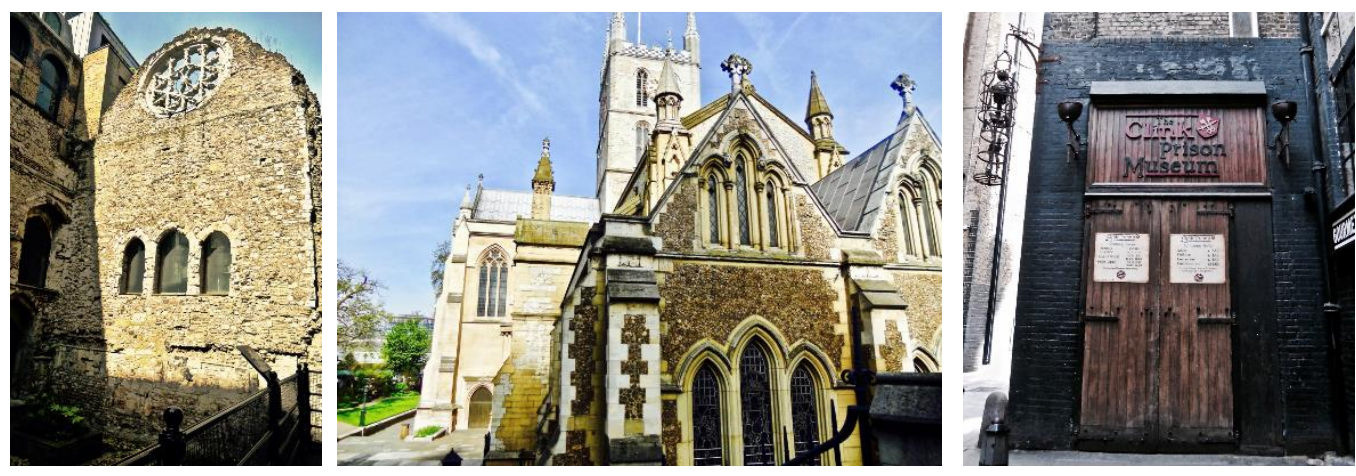

Fuente: Autora. Bankside, 2016

\footnotetext{
1 "La City de Londres siempre miró a Southwark con desconfianza. Aunque reconoció a la ciudad como un lugar vibrante, activo y productivo, y por lo tanto como una fuente potencial de ingresos, no le gustaba tener un vecino tan grande, autónomo e impredecible a sus puertas" (traducción de la autora).

2 "Gansos de Winchester" en castellano.
} 
Southwark era una zona que sufría múltiples inundaciones y su carácter pantanoso hacía que la insalubridad y la pestilencia se multiplicaran aún más. La muerte acabó con muchas de las personas que habitaban Bankside, sobre todo de aquéllas que vivían en las pequeñas casas del suburbio. En las plagas que tuvieron lugar entre los siglos XV y XVII - entre ellas la denominada Black Death ${ }^{3}$ - se cavaron grandes fosas comunes para enterrar a los y las que habían perdido la vida. Nuevas epidemias y plagas aparecían en la zona constantemente teniendo que optar nuevamente por las fosas comunes como solución ante las numerosas muertes - tal es el caso de la epidemia que precedió el Gran Incendio de Londres de 1666-(Golden, 1951). A pesar de estar bajo la protección de la Iglesia, las "Winchester Geese" que fallecieron a causa de tales epidemias también fueron enterradas en fosas comunes puesto que a su muerte no se les permitió un entierro cristiano. "Even though they worked under the official protection of the Church, these prostitutes were excluded from Christian burial. Instead they were buried in shallow unmarked graves with no more than quicklime to warm their bones. The unconsecrated land that holds their syphilitic bodies is called Cross Bones Graveyard"4 (Harris, 2010: 2).

Las "Winchester Geese" caían así en el olvido sin importar su nombre, religión, inquietudes o valores no sólo a lo largo de su vida, sino también de su muerte. Lo que ellas no sabían es que con el paso de los años recibirían el respeto que merecían generando un movimiento que lleva en pie más de dos décadas. Entre 1991 y 1998 se realizaron una serie de excavaciones arqueológicas en Redcross Way debido a la construcción de una extensión del metro de Londres donde se encontraron miles de esqueletos que fueron analizados por forenses concluyendo que muchos de ellos pertenecían a mujeres y niños - de los que varios correspondían a bebés-. Una vez iniciadas esas excavaciones el pasado de Bankside empezó a emerger invitando a la población del Distrito a revivir y recordar lo que había pasado en su etapa como barrio rojo dando sobre todo a conocer la historia de aquellas mujeres cuyos esqueletos se encontraban enterrados en esa zona olvidada, pero pronto valorada gracias al resurgir de Crossbones ${ }^{5}$. "Although some locals knew the story of Cross Bones, it had long remained a fairly obscure piece of Southwark history. Cross Bones had become a builder's yard: just another piece of derelict land fenced, gated and almost forgotten. But that was about to change"6 (Harris, 2010: 2).

\footnotetext{
${ }^{3}$ Conocida como Peste Negra en castellano.

4 "Aunque trabajaban bajo la protección oficial de la Iglesia, estas prostitutas fueron excluidas del entierro cristiano. En lugar de eso fueron enterradas en tumbas poco profundas y sin distintivos, sin más que cal viva para calentar sus huesos. La tierra no consagrada que contiene sus cuerpos sifilíticos se llama Cross Bones Graveyard" (traducción de la autora).

${ }^{5}$ Dependiendo de la fuente, "Crossbones" aparece escrita como una única palabra o como dos -"Cross Bones"-. Para la redacción de este artículo se ha optado por la unión de ambas palabras -"Crossbones"-Sin embargo, en las citas incluidas en este estudio se mantendrá la redacción original.

6 “Aunque algunos lugareños conocían la historia de Cross Bones, había permanecido por mucho tiempo como una pieza bastante oscura de la historia de Southwark. Cross Bones se había convertido en un patio para constructores: simplemente otro pedazo de tierra abandonada cercada, cerrada y casi olvidada. Pero eso estaba a punto de cambiar" (traducción de la autora).
} 


\section{Objetivos y metodología}

El presente artículo forma parte de la investigación Los cinco sentidos del Distrito Cultural en Londres siendo uno de sus objetivos principales el establecer una metodología que permita estudiar un Distrito Cultural dando el mismo protagonismo a cada uno de los cincos sentidos vista, oído, tacto, gusto y olfato-. A su vez, se persigue concienciar -no sólo en cuanto al ámbito turístico se refiere, sino también por lo que al ámbito de la investigación respecta- sobre la importancia de descubrir un Distrito de forma multisensorial sin que el sentido de la vista predomine sobre los demás. Siguiendo el método iconológico de Erwin Panofsky y tomando como referente el Atlas Mnemosyne de Aby Warburg, se construyó un Atlas Multisensorial para analizar algunos de los Distritos Culturales de Londres - comenzando por Bankside- dando un protagonismo igualitario a los cinco sentidos.

\subsection{Cosmos de cultura y estructura espacio-temporal}

Erwin Panofsky hacía referencia a cómo el humanista fechaba y localizaba el material primario del que disponía para poder así obtener un cosmos de cultura al que consideraba como una estructura espacio-temporal donde todos los elementos se observaban, se relacionaban con otros materiales, se organizaban y/o clasificaban y se interpretaban o descifraban (Panofsky, 1979: 21-25).

Para la presente investigación, se llevó a cabo un cosmos de cultura para Bankside a través de la recopilación de la información y demás material disponible del Distrito. Así, se realizó una primera organización atendiendo a las siguientes variables:

- Autoría: o en su caso dirección o presidencia de las organizaciones, museos, galerías e instituciones.

- Tiempo: fecha en la que se realizó una determinada obra, monumento, edificio, evento, su duración y los horarios de apertura y cierre (de los locales de la zona, museos, tiendas, bares, restaurantes, instituciones).

- Espacio: dónde tenían lugar exactamente las obras, exposiciones, actividades y demás eventos (en calles, plazas, museos, restaurantes, locales...) además de las diferentes Páginas Web y redes sociales donde se pudiera encontrar información del material analizado.

\subsection{Atlas Multisensorial}

La organización planteada del cosmos de cultura para Bankside se asemejaba a lo que Aby Warburg presentó como Atlas Mnemosyne. Los textos literarios se cotejaban de forma conjunta con las obras de arte permitiendo de esta forma aproximarse a lo que la sociedad de esa época en concreto sentía respecto a las obras de arte que se habían realizado en aquel contexto (Gombrich, 1992: 94). 
En el Atlas planteado por Aby Warburg sólo se incluía imagen y texto, sin embargo para el presente estudio se decidió crear un Atlas mucho más flexible donde se incluyeron sonidos, vídeos, imágenes e incluso texturas obteniendo un Atlas Multisensorial donde tendrían cabida los cinco sentidos de una forma clara y ordenada gracias a las nuevas tecnologías ${ }^{7}$. Dicho esto, siguiendo con la organización planteada por Warburg, se reagruparon las imágenes y demás material recopilado con anterioridad en ocho temáticas junto con sus respectivas organizaciones espacio-temporales, encontrándonos así con ocho series -(a) museos y galerías; (b) cines, teatros y espectáculos; (c) festivales, eventos y actividades culturales; (d) monumentos y construcciones civiles; (e) espacios abiertos; (f) gastronomía; (g) tiendas y (h) alojamientos-compuestas a su vez por diferentes paneles, entre los cuales se encontraba el panel Crossbones ubicado en la serie (d) monumentos y construcciones civiles.

\subsection{Método iconológico de Erwin Panofsky}

Para poder realizar los paneles del Atlas Multisensorial adecuadamente y llevar a cabo una buena interpretación del material recopilado se siguió el método iconológico de Erwin Panofsky, el cual consiste en tres niveles (Panofsky, 1979: 45-60):

a) Nivel pre-iconográfico: descripción detallada de la imagen identificando formas, colores, líneas, perspectivas, número de figuras, vestimenta, luces, decorado, gestos, etc. Una vez adaptado este primer nivel de análisis a los cinco sentidos, no sólo se describiría detalladamente la imagen, sino también el gusto, sonido, aroma/ambiente o actividad objeto de estudio atendiendo por lo tanto también a las texturas, olores, sabores, melodías y densidades entre otras variables.

b) Nivel iconográfico: se lleva a cabo una clasificación del material atendiendo al espacio y al tiempo sin realizar ningún tipo de interpretación necesitando un conocimiento previo de fuentes literarias y una familiaridad con temas y conceptos específicos. En esta segunda fase, se organizarían las series de paneles llevando a cabo una clasificación exhaustiva de todo el material disponible una vez realizado un estudio previo y una primera toma de contacto.

c) Nivel iconológico: interpretación final donde se tiene en cuenta al artista, el contexto histórico y cultural, la intencionalidad, la función y el significado. Para ello, es necesario un gran conocimiento de la historia del arte, así como de todo tipo de textos y fuentes, puesto que hay que explicar y descifrar una imagen -en nuestro caso también un sonido, aroma, sabor o acción y/o textura- aportando no sólo una interpretación personal, sino basándose en toda una serie de conocimientos previamente aprehendidos.

\footnotetext{
${ }^{7}$ Aby Warburg hablaba de paneles y en nuestro caso por ejemplo podemos hablar de carpetas y subcarpetas ubicadas en el ordenador y organizadas según la clasificación previamente establecida.
} 


\subsection{Serie d) - Panel 1: Crossbones}

Tras la recopilación de la documentación relacionada con Crossbones procedente de varios archivos londinenses y diferentes páginas oficiales, se visitó el lugar donde se localizaba dicho emplazamiento atendiendo a los cincos sentidos y realizando diferentes grabaciones sonoras para su posterior estudio y relación con los demás paneles y materiales disponibles.

De su relación con los cinco sentidos, el que más cabe destacar en este caso es el del tacto, puesto que dentro de éste no sólo se aludiría a las texturas que podamos encontrar en el objeto de estudio, sino también a la intervención ciudadana de forma activa. Como se podrá observar a continuación, Crossbones se mantiene gracias a la participación no sólo de los habitantes de Bankside, sino de todas aquellas personas que quieran involucrarse en menor o mayor medida en su desarrollo y conservación. Así, se consigue concienciar a la población sobre la importancia de ahondar más en la historia y conocer la situación real por la que mujeres como las conocidas por las "Winchester Geese" tuvieron que vivir en su época no sólo denegándoles un entierro digno, sino incluso olvidando que cada una de ellas era una persona digna de respetar como cualquier otro/a ciudadano/a que habitase las tierras de Bankside.

En este artículo se podrá comprobar cómo gracias a la participación ciudadana, las "Winchester Geese" dejan de ser sólo conocidas como mujeres que ejercieron la prostitución en los burdeles del Distrito a mujeres que son conmemoradas y cuyos nombres, apellidos y demás información que se pueda recopilar sobre sus vidas son recordados y honrados. Asimismo, el público deja de ser un mero espectador para ser un sujeto activo que hace posible la continuidad de espacios como Crossbones convirtiéndose en una pieza clave para su creación y desarrollo. A su vez, se hace posible una relectura de la historia del Distrito con su consecuente concienciación ciudadana permitiendo la difusión de un pasado que cayó en el olvido.

\section{El descubrimiento de Crossbones Graveyard}

El 23 de noviembre de 1996 un dramaturgo conocido como John Constable escuchó el susurro del espíritu de una mujer que se auto denominaba como "The Goose ${ }^{8 "}$-recuérdese cómo las mujeres que ejercían la prostitución en Bankside eran conocidas como las "Winchester Geese"-. Esa primera toma de contacto con "The Goose" le inspiró para escribir el primero de varios poemas y obras que recogió en The Southwark Mysteries. A pesar de no tener conocimiento de la existencia del emplazamiento de esa especie de cementerio en Redcross Way, pasado un tiempo se dio cuenta de que el espíritu apareció durante las excavaciones realizadas bajo la orden del Transport for London -TfL- indagando seguidamente en la historia de Crossbones.

8 Goose -“ganso" en castellano- es el singular de Geese. 
The Southwark Mysteries ${ }^{9}$ sirvió de inspiración para llevar a cabo el primer Halloween entorno a Crossbones el día 31 de octubre de 1998 liderado por John Constable y celebrado anualmente desde entonces. Además, desde el 23 de junio de $2004^{10}$ también se llevan acabo una serie de vigilias mensuales en memoria de las mujeres que se encuentran allí enterradas.

\begin{abstract}
"The establishment of a garden of remembrance will unite Londoners in a shared project: to protect our heritage for future generations, creating a green public space in an area currently undergoing the disruption of massive construction projects. Cross Bones is already a unique Heritage Site, a truly inclusive memorial to 'the outcast dead' and to the ordinary working poor of London"11 (Constable en BOST, 2015b: 3).
\end{abstract}

Gracias a las campañas realizadas por los y las residentes locales y movimientos como Friends of Crossbones Graveyard ${ }^{12}$ junto al dramaturgo John Constable, el Consejo de Southwark decidió evitar el deterioro o construcción en la zona. En el año 2008 Transport for London se comprometió a proteger el área donde se emplazaba el cementerio y un año más tarde el Community Project Bank del Consejo de Southwark aseguró que ninguna renovación o urbanización afectaría a la conservación del cementerio. Desde el año 2010, Friends of Crossbones Graveyard han luchado junto a Bankside Open Spaces Trust (BOST) ${ }^{13}$ por la conservación y la creación de un jardín conmemorativo en la zona -el cual fue diseñado por Helen John contando también con la ayuda del misterioso "Invisible Gardener"14_. En el año 2014 Transport for London garantizó el establecimiento de una renta para poder llevar a cabo el jardín abriendo por fin sus puertas al público en el 2015 (Berns, 2016).

"At a time when green spaces are being swallowed up by new developments and when tourism has become a vital part of the local economy, we have the opportunity to ensure that any commercial development also serves to establish a public park and heritage site, a community garden and visitor

\footnotetext{
${ }^{9}$ Las obras y poemas recogidos en The Southwark Mysteries han sido representados al completo en Shakespeare's Globe y en Southwark Cathedral en los años 2000 y 2010 además de representarse en menos escala durante las vigilias y rituales que se han llevado a cabo en las inmediaciones de Crossbones Graveyard (Constable en BOST, 2015a).

${ }^{10}$ Estas vigilias se celebran desde entonces todos los días 23 de cada mes a las siete de la tarde. Su duración es variable y los rituales y actos que allí se celebran son muy similares a los realizados durante las noches de Halloween, aunque de forma menos extensa.

11 "La creación de un jardín conmemorativo unirá a los londinenses en un proyecto compartido: proteger nuestro patrimonio para las generaciones futuras, creando un espacio público verde en una zona que está sufriendo actualmente alteraciones debidas a grandes proyectos de construcción. Cross Bones ya es un Patrimonio único, un verdadero homenaje abierto al público de los 'marginados muertos' y de los trabajadores pobres de Londres" (traducción de la autora).

${ }^{12}$ Friends of Crossbones Graveyard es un grupo que se creó entorno a la historia de Crossbones para luchar por su permanencia, conservación y conmemoración.

${ }^{13}$ Alrededor del año 2000 el Consejo de Southwark decidió crear una organización para la mejora y desarrollo de pequeños espacios al aire libre en desuso a través de la colaboración de la comunidad local surgiendo así lo que ahora se conoce como Bankside Open Spaces Trust -BOST-.

${ }^{14}$ El "Jardinero Invisible" en castellano.
} 
attraction in the very heart of London"15 (Constable en BOST, 2015b: 11).

Con la puesta en marcha del jardín y gracias a su difusión a través de los medios de comunicación, Crossbones fue dándose a conocer cada vez más consiguiendo que sus vigilias mensuales crecieran en número y fuerza atrayendo así no sólo a los habitantes de Bankside, sino a turistas y a gente de paso (Berns, 2016). A pesar de que el jardín no se encuentre abierto constantemente, todos los que pasan por allí pueden aprender la historia de Crossbones e informarse de las acciones que se realizan en torno a éste gracias a los carteles que se encuentran localizados en el exterior. Además, las verjas son una auténtica exposición donde se pueden visualizar toda una serie de lazos y objetos que sirven como ofrenda para las "Winchester Geese" y que los y las participantes de las vigilias allí realizadas han ido depositando permitiendo así una renovación continua del espacio.

"Our vision is for a garden led by local people that shows respect to the many nameless women, children and men buried here, and provides a sensitive contemplative environment for all who would spend time here. Visitors will be able to experience living history in the setting of a beautiful garden of recognition"16 (Desmond en BOST, 2015b: 3).

Figuras 4 y 5. Cartel y placa informativa de Crossbones
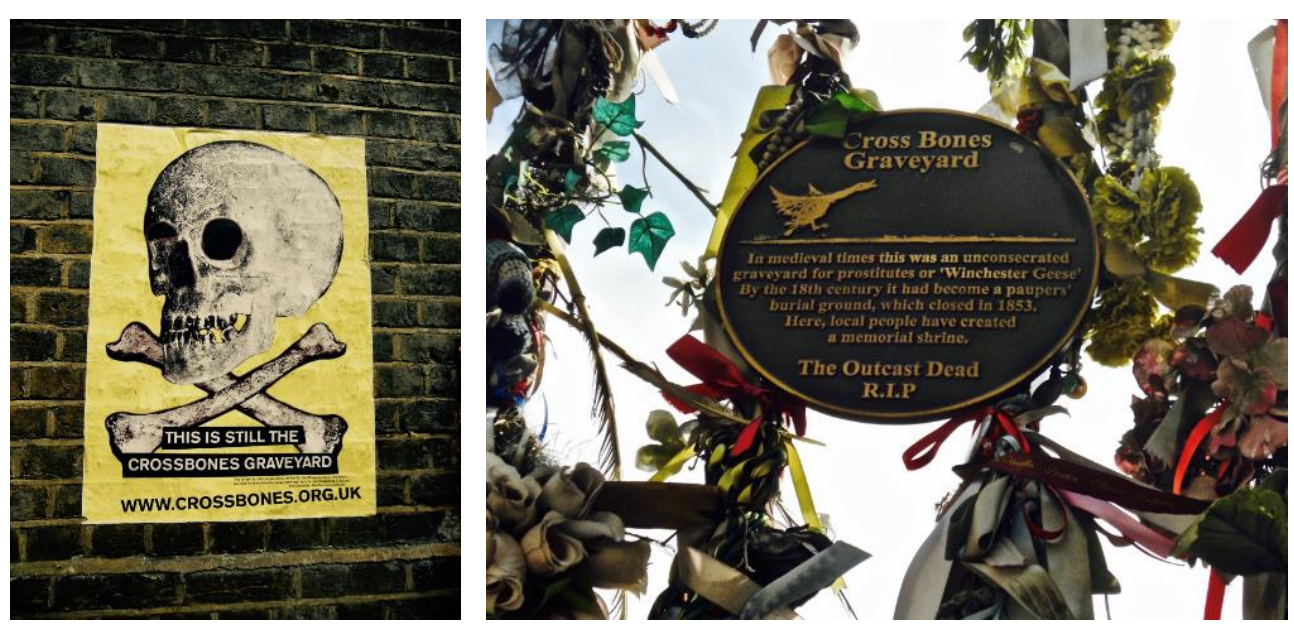

Fuente: Autora. Bankside, 2016

\footnotetext{
15 "En el momento en el que los espacios verdes están siendo absorbidos por nuevos desarrollos y cuando el turismo se ha convertido en una parte vital de la economía local, tenemos la oportunidad de garantizar que cualquier desarrollo comercial también sirve para establecer un parque público y un lugar patrimonial, un jardín comunitario y una atracción para los visitantes en el mismo corazón de Londres" (traducción de la autora).

16 "Nuestra visión es para un jardín dirigido por la gente local que muestra respeto por las numerosas mujeres sin nombre, niños y hombres enterrados aquí, y proporciona un sensible ambiente contemplativo para todos los que pasen tiempo aquí. Los visitantes podrán experimentar la historia viva en el escenario de un hermoso jardín de reconocimiento" (traducción de la autora).
} 


\section{Ceremonias y ofrendas para las "Winchester Geese"}

Crossbones Graveyard no sólo consiste en un santuario y un jardín conmemorativo para rendir homenaje a las "Winchester Geese", sino en un punto de encuentro para recordar a cada una de ellas dándoles el valor y reconocimiento que se merecen. Tanto en la noche de Halloween como en las vigilias mensuales, cada participante lleva en su muñeca un lazo blanco donde aparece escrito el nombre, la dirección, profesión y año de la muerte de cada una de las personas cuyos cuerpos permanecen allí enterrados. El pasado y el presente se funden constantemente en los rituales que se celebran entorno a Crossbones apareciendo incluso mujeres que llevan los vestidos isabelinos que las plebeyas de la época llevaban sobre sus cuerpos -entre ellas las "Winchester Geese"-.

Las actividades realizadas a lo largo de esos eventos se realizan en el exterior junto a las verjas que rodean el jardín dando la posibilidad de dejar todo tipo de obsequios en éstas pequeños juguetes, poemas, flores, velas, muñecas...-. Se realizan procesiones con velas, incienso, canciones y todo tipo de ofrendas lideradas por John Constable quien actúa bajo el nombre de John Crow durante los rituales y recita varios de los poemas recogidos en su obra The Southwark Mysteries (Harris, 2010).

Figura 6. Ofrendas en las rejas de Crossbones

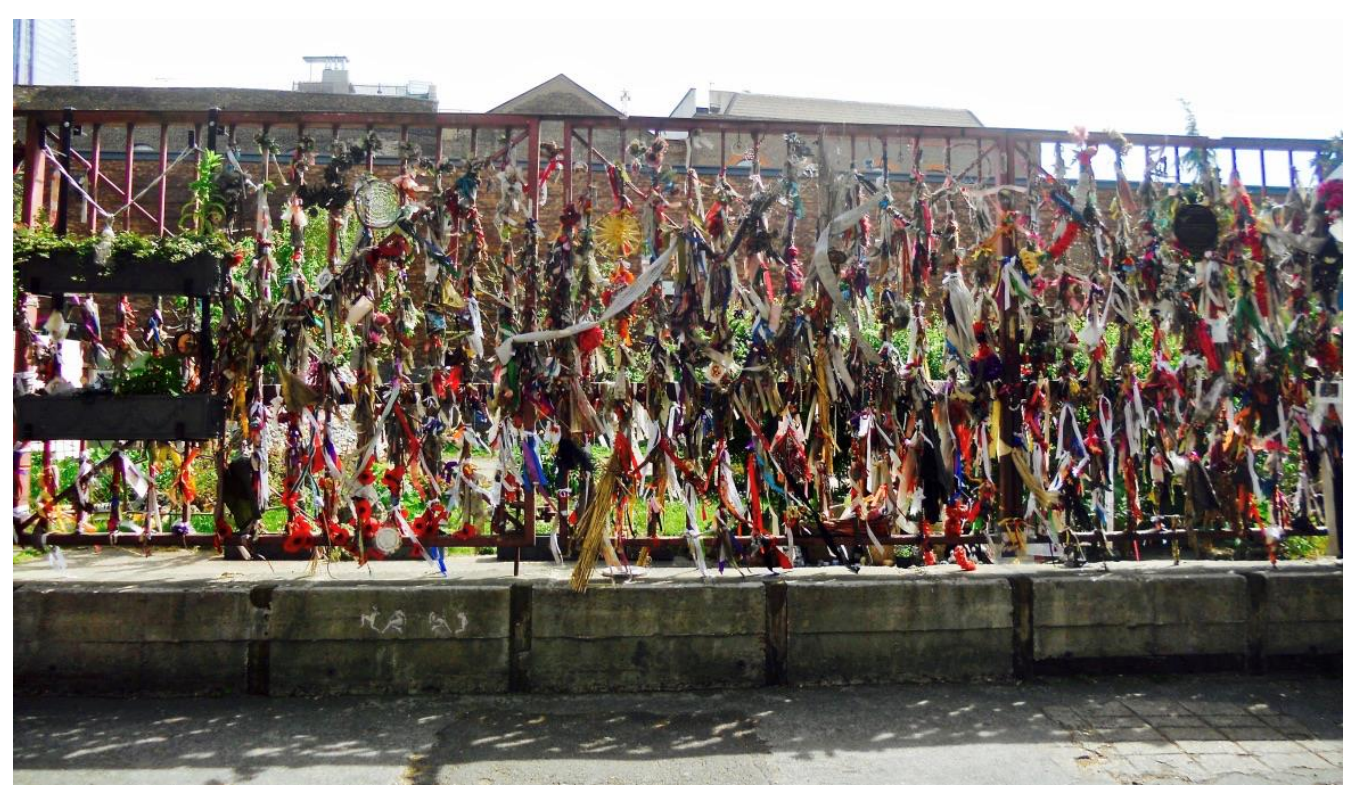

Fuente: Autora. Bankside, 2016

De esta forma, esas mujeres caídas en el olvido y sumidas en una infravaloración constante 
a lo largo de sus vidas vuelven a tener presencia en el día a día de Bankside. Una presencia que de cierto modo consigue su inmortalidad, puesto que su espíritu impregna no sólo el jardín que se ha creado en su memoria, sino cada una de las ofrendas que la gente deposita en su honor. Gracias a ellas, temas como la prostitución, la sexualidad y los derechos de la mujer se visibilizan cada vez más sin distinción de raza, edad o religión. Todas aquellas personas que quieran formar parte de este movimiento quedan invitadas, puesto que la diversidad tanto en religiones como en procedencias se entremezclan sin distinción alguna enriqueciendo incluso el lugar. Y es que uno de los elementos clave para que Crossbones siga en pie es la participación activa de los y las participantes no sólo en las vigilias, sino en la conservación del jardín, en su colaboración a través de donativos y ofrendas que renuevan el espacio constantemente y en su implicación a la hora de concienciar a la población sobre el papel de la mujer en la prostitución y la libre expresión sobre temas como la sexualidad y la espiritualidad femenina "We gathered to celebrate the sacred aspects of sexuality and to honour those buried in the graveyard, especially the Winchester Geese. The festival combines reverence with bawdy humour and although is rooted in contemporary Paganism, it integrates elements of gnosticism, Buddhism, Tantra and spiritualism" ${ }^{17}$ (Harris, 2010: 5).

Este tipo de rituales y ceremonias son cada vez más frecuentes no sólo alrededor de Crossbones, sino a nivel internacional existiendo movimientos como el denominado Reclaiming donde la espiritualidad de la mujer cobra protagonismo teniendo como su principal pilar de apoyo la veneración a la Diosa. Los cuatro elementos -aire, tierra, agua y fuego- aparecen siempre en sus rituales donde de nuevo la diversidad está presente en todo momento ${ }^{18}$.

\section{El santuario: mitología, simbología y energía femenina}

Tal y como se ha comentado anteriormente, las "Winchester Geese" recibían ese apelativo porque pagaban una serie de tasas al Obispo de Winchester para poder así ejercer su trabajo. Sin embargo, tras realizar un análisis de contenido de toda la documentación recopilada al respecto, no se ha encontrado ninguna explicación que especifique de forma concreta por qué se aludía a ellas como gansos. No obstante, dicha relación podría deberse a la representación de varios

\footnotetext{
17 "Nos reunimos para celebrar los aspectos sagrados de la sexualidad y para honrar a aquellos [/as] que han sido enterrados [/as] en el cementerio, especialmente a las 'Winchester Geese'. El festival combina la veneración con el humor grosero y aunque está arraigado en el Paganismo contemporáneo, integra elementos del gnosticismo, del Budismo, del Tantra y del espiritismo" (traducción de la autora).

18 "Somos parte de un movimiento más amplio denominado la espiritualidad feminista, que critica los modos de dominio establecidos en las religiones patriarcales y reinventa una espiritualidad que pueda ser liberadora tanto para hombres como para mujeres. Para nosotros, esta nueva visión alimenta sus raíces en la Diosa, el ser que representa los ciclos del nacimiento, crecimiento, muerte, descomposición y renovación que hallamos tanto en la Naturaleza como en nuestras vidas humanas" (Starhawk, 2001: 18).
} 
Obispos y/o santos junto a dicha ave como es el caso de San Hugo de Licoln, San Hugo de Grenoble o San Martín, entre otros, siendo un símbolo ya habitual entre la religión cristiana. De ahí que el apelativo de gansos pueda corresponderse con su consideración como meras acompañantes y/o atributos del Obispo dependiendo incluso de éste para poder subsistir.

Sin embargo, con la creación de Crossbones Graveyard y las actividades que se llevan a cabo entorno a éste, la figura del ganso ha adquirido un significado totalmente diferente alejado de ideas como la dependencia o la compañía. La figura del pájaro nos conduce al vuelo, la ascensión e incluso a nuestros antepasados recordando culturas y antiguos rituales que siguen persistiendo de algún modo y donde las mujeres aladas no dejan que las grandes diosas de la vida y la muerte caigan en el olvido. ¿Sería por ese motivo que uno de los espíritus de esas mujeres logró llamar la atención de John Constable?

Son numerosas las ocasiones en las que las mujeres adoptan la forma de un pájaro no sólo en cuanto a mitología se refiere, sino que esta transformación también aparece en varios cuentos donde las princesas adquieren la forma de un cisne al haber sido víctimas de un castigo o maleficio. E incluso a veces no es una, sino varias mujeres las que se transforman en este ave de manera grupal como sucede en el relato de Wieland el Herrero donde tres chicas podían adoptar el aspecto de un cisne siempre que lo desearan gracias a sus ropajes mágicos. Asociado en varias ocasiones con la muerte, algunos de los personajes femeninos que protagonizan varias historias, cuentos o mitos emprenden un viaje hacia el inframundo adoptando de nuevo la figura de un cisne -véanse por ejemplo las valquirias nórdicas quienes eran consideradas como guerreras que suelen aparecer armadas, montando caballos alados y portando en la mayoría de los casos un casco con alas (May, 2000)-.

El cisne y el ganso tienen una estrecha relación confundiéndose en diversas ocasiones tal como sucede en la mitología hindú donde ambas aves se vinculan con las cosmogonías, la Sabiduría Divina y/o de las Tinieblas: "En lo exotérico, Hamsa [...] es un ave fabulosa a la que cuando se le da leche mezclada con agua (en la alegoría), las separa, bebiéndose la leche y dejando el agua, mostrando así sabiduría propia; pues la leche representa simbólicamente al espíritu, y el agua a la materia" (Blavatsky, 2000: 179). Por lo tanto, hay una dualidad constante en la figura de las aves asociada tanto a la vida como a la muerte. Dualidad que nos transporta a la Era del Paleolítico recordando así a las denominadas Diosas Pájaro:

"La Diosa Pájaro era la encargada de proveer la humedad vital que precisaba el conjunto de la vida para seguir existiendo, y como ave acuática, representaba el nexo de unión entre la tierra y el cielo [...]. Sus elementos característicos, máscara o rostro con pico de ave, pechos, brazos en forma de alas y grabaciones con simbolismo acuático y pubiano, la muestran como fuente divina del alimento vital leche y lluvia- o como donante de vida en general, eso es como la Diosa Donante de Vida. [...] también era la Diosa de la Muerte cuando adoptaba la forma de ave de presa-fundamentalmente buitre y búho, aunque también cuervo o halcón- [...]. Se creía que la muerte era un paso hacia la vida, y ese proceso tenía lugar dentro de la tumba, eso es del útero simbólico de la Gran Diosa en su función de Diosa de la Muerte y la Regeneración” (Rodríguez, 1999: 218, 219). 
Por lo tanto, cabría decir que los "Gansos de Winchester" adquieren un carácter mitológico que incluso trae al recuerdo nuestros orígenes más primitivos mediante la figura del ave. Un ave que les acompañó no sólo a lo largo de su vida, sino también en su muerte y que reaparece constantemente ya sea a través del ganso que susurró a John Constable o mediante las diversas ocasiones que aparece como signo distintivo cual montura o atributo propio de diosas como Afrodita o Sarasvati ${ }^{19}$. Incluso en la entrada del jardín se puede observar una enorme ala de ganso de madera ${ }^{20}$ que vuelve a aludir a este animal convirtiéndose en un elemento indispensable y característico de Crossbones Graveyard (ver fig. 7). De esta forma, las "Winchester Geese" dejan de ser atributos o acompañantes del Obispo de Winchester a ser las verdaderas protagonistas siendo el ganso uno de sus elementos característicos.

Figura 7. "Goose Wing” de Arthur DeMowbray

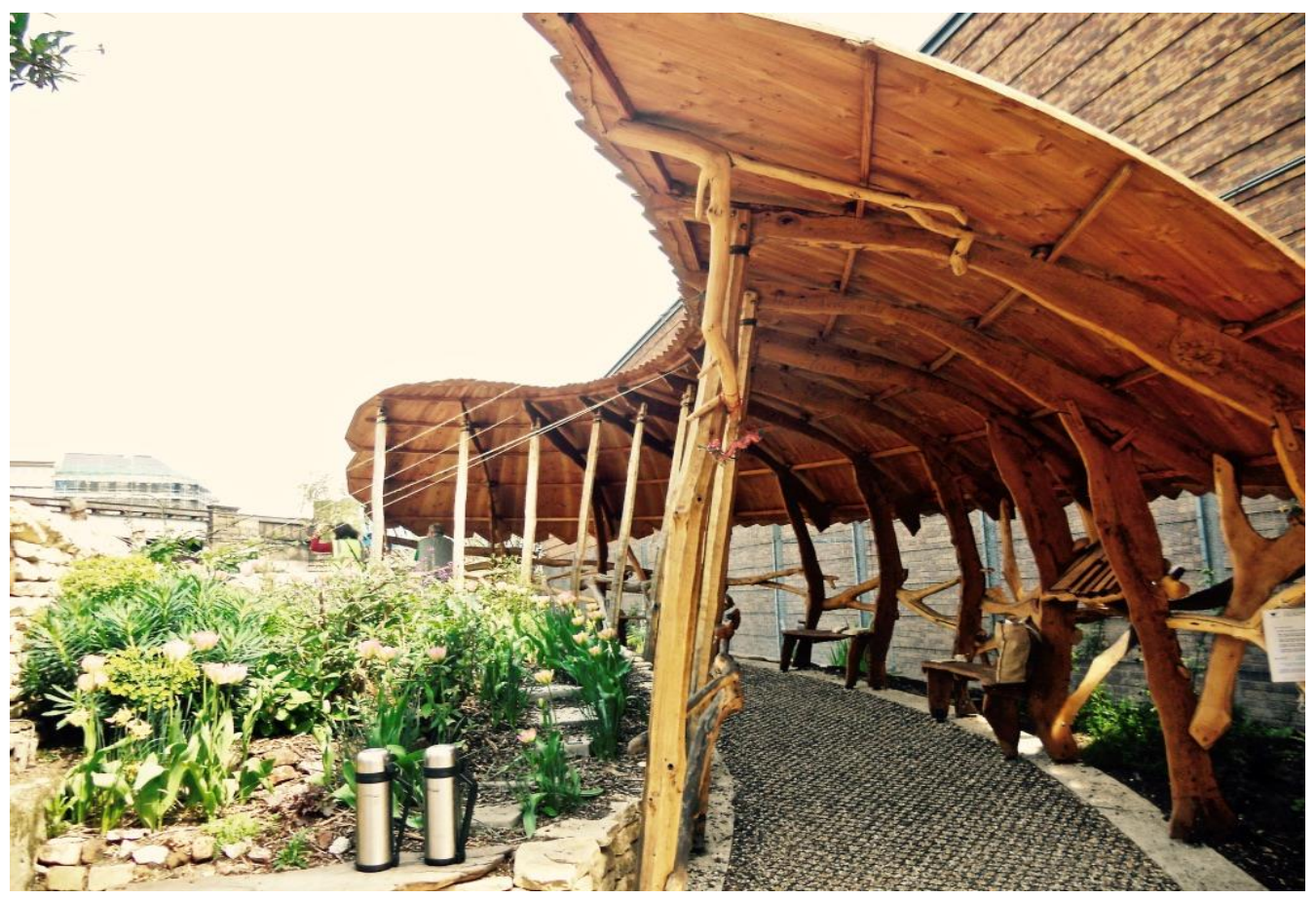

Fuente: Autora. Bankside, 2016

Pero no son solo los "Gansos de Winchester" las que se relacionan estrechamente con la

\footnotetext{
${ }^{19}$ Relacionada con la música y la poesía, la diosa-río Sarasvati aparece junto a la figura de un cisne, siendo incluso éste su propia montura (Schleberger, 2004).

${ }^{20}$ Inicialmente iba a construirse para permitir el acceso con silla de ruedas, pero antes de llevar a cabo su construcción el autor de esta entrada -Arthur DeMowbray- tras reunirse con los Friends de Crossbones y asistir a varias vigilias decidió representar en ese acceso la mitología urbana existente en ese jardín conmemorativo (Berns, 2016).
} 
figura del pájaro, sino incluso que John Constable adopta el nombre de John Crow -John Cuervo en castellano- a la hora de liderar las ceremonias y rituales alrededor de Crossbones recordándonos así la figura del chamán e incluso dioses nórdicos como Odín considerado en diversas ocasiones como brujo o chamán y estrechamente relacionado con las valquirias quienes además de transformarse en aves como el cisne también poseen la habilidad de cambiar su forma en cuervos ${ }^{21}$ - considerados como los mensajeros de Odín-.

\footnotetext{
"Aunque algunos (pocos) han puesto en duda el carácter chamánico de Odín, basta con echar un vistazo a las más importantes coincidencias entre el 'Consejero Falso' y los chamanes del norte: sufren muerte aparente para poder desplazarse en busca del conocimiento; tratan con seres de ultratumba, a quienes interrogan; viajan en forma de animal; suelen ir acompañados de aves como el cuervo; tienen espíritus femeninos que los acompañan en sus vuelos, como las valquirias; y pueden averiguar el pasado, el presente y el futuro, conocimiento que está vedado a todos los demás” (Bernárdez, 2002: 210).
}

Figuras 8 y 9. La "Madonna" de Crossbones y detalle de las ofrendas en las verjas
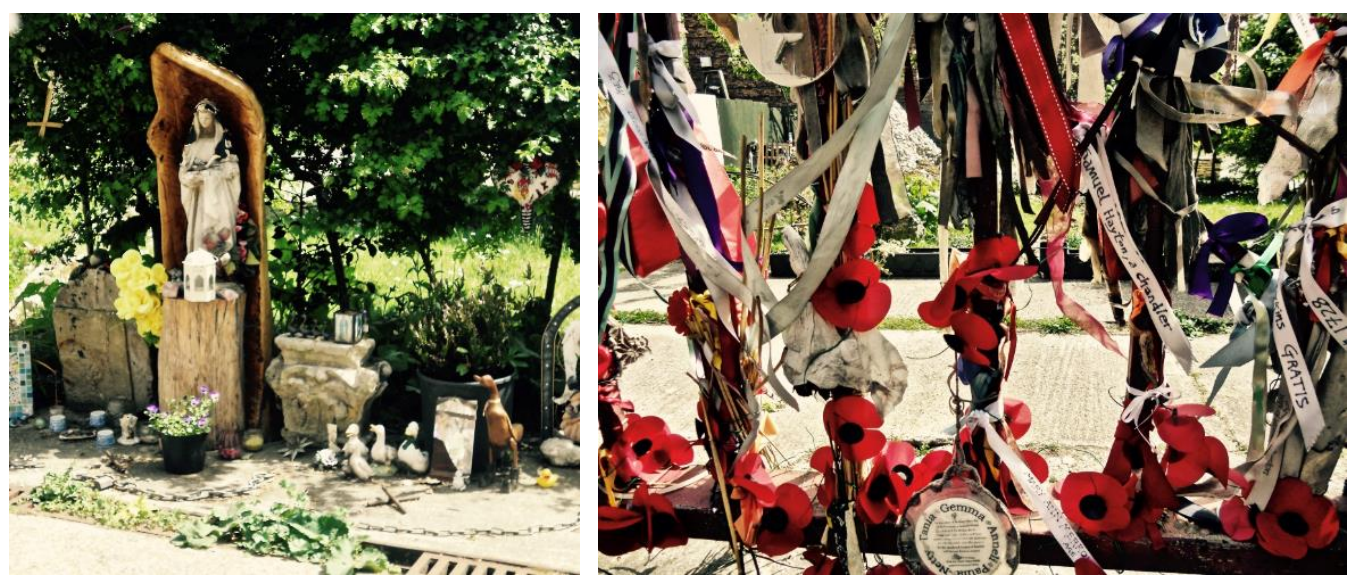

Fuente: Autora. Bankside, 2016

Justo detrás de las verjas colmadas de ofrendas y lazos, se puede visualizar la figura de lo que parece ser una Madonna cristiana portando entre sus brazos un pequeño ganso además de estar también acompañada de varias de estas aves en diferentes materiales y tamaños (fig. 8). Por ello, aunque a simple vista parezca un icono cristiano, los elementos que le rodean nos llevan también a considerarla como una verdadera diosa pagana encontrándonos de nuevo una

\footnotetext{
21 "Demiurgo y héroe civilizador, clarividente y profeta, pájaro solar y a la vez tenebroso, anuncia desgracia y muerte y a veces protege. Esta ambivalencia proviene de sus propiedades físicas variadas, pudiendo cada una de ellas servir de soporte de una interpretación simbólica" (Chevalier; Gheerbrant, 2007: 391).
} 
diversidad de creencias y religiones fruto de la colaboración de los y las que participan para que Crossbones no desaparezca. Nos encontramos así ante la creación de una nueva divinidad femenina contemporánea que engloba numerosas cualidades y características que recoge de diferentes creencias y religiones donde los cuatro elementos -aire, agua, tierra y fuego- también están del todo presentes. A pesar de ser el elemento del aire el gran protagonista, no hay que olvidar la presencia de la tierra a través de la creación del jardín conmemorativo e incluso aludiendo a la figura del árbol como gran contenedor -véase cómo la escultura de la Madonna se encuentra en el interior de esa especie de abertura perteneciente al tronco de un árbol (fig. 8)-. El fuego, el cual es un elemento transformador que se encuentra presente en muchos ritos y ceremonias, aparece representado a través de los tonos rojizos que abundan en las rejas de las ofrendas (fig. 9) y las velas -tanto las que se utilizan durante los rituales y ceremonias como las que se depositan junto a la Madonna-. Y, por último, el agua no sólo aparece reflejado en la figura del ganso -puesto que es considerado como un ave acuática-, sino también mediante la introducción de otros elementos como son los espejos, una pirámide cubierta de conchas e incluso un pequeño estanque en forma de triángulo invertido.

La espiritualidad es un pilar clave en Crossbones siendo representada por las aves que nos llevan a la ascensión y/o al vuelo y mediante diferentes elementos ubicados en el interior del jardín como la figura de la pirámide ${ }^{22}$ y el triángulo - el cual, además de considerarse como símbolo femenino al tener su vértice invertido, está relacionado con la espiritualidad que desciende a la tierra ${ }^{23}$-. Espiritualidad presente también en las vigilias y ritos celebrados cada 31 de Octubre donde las ofrendas, los cantos y las procesiones acompañan a los espíritus honrados. E incluso, espiritualidad que va ligada a la sexualidad femenina representada a través de diferentes símbolos como las numerosas conchas de ostras ${ }^{24}$ que cubren la pirámide que se encuentra en el interior del jardín conmemorativo creada por el "Invisible Gardener". Volviendo al carácter sexual de las conchas, cabe decir que la similitud de ciertas ostras y conchas con los órganos sexuales femeninos hacen que su vinculación con la mujer se reafirme ${ }^{25}$. Además de ser reconocidas como recursos mágicos utilizados a modo de amuletos y elementos decorativos para favorecer la fecundidad, sirven para evitar todos aquellos males que puedan resultar nocivos

\footnotetext{
22 "Convergencia ascensional, conciencia de síntesis, la pirámide es también lugar de encuentro entre dos mundos: un mundo mágico ligado a los ritos funerarios de retención indefinida de la vida o de paso a una vida supratemporal; un mundo racional, que evoca la geometría y los modos de construcción" (Chevalier y Gheerbrant, 2007: 838).

${ }^{23}$ El triángulo a su vez se asocia con el tres aludiendo en la alquimia al fuego, al plano espiritual y al corazón. Asimismo, este mismo número se encuentra también en los colores básicos del Opus Magnum: negro, blanco y rojo representados a través de los tres pájaros (Autora, 2013: 143).

${ }^{24}$ Las ostras eran consideradas además como un alimento propio de los pobres, puesto que antes del siglo $\mathrm{XX}$ eran muy baratas $\mathrm{y}$, por lo tanto, seguramente que formaron parte de los alimentos que muchas de las allí enterradas consumían en aquella época (Página Oficial Crossbones, n.d: n.p. Disponible en: http://crossbones.org.uk/history/ [16/01/2017].

25 "Participan todas, en efecto, de los poderes sagrados concentrados en las Aguas, en la Luna, en la Mujer; además, y por diversas razones, son emblemas de estas fuerzas: semejanza entre la concha marina y los órganos genitales de la mujer, relaciones que unen a las ostras, las aguas y la luna; en fin, simbolismo ginecológico y embriológico de la perla, formada en la ostra" (Eliade, 1992: 137).
} 
siendo considerada también como símbolo propio de la resurrección o segundo nacimiento -los alquimistas utilizaban incluso la expresión "concha de oro" para referirse a la consecución de la piedra filosofal- volviendo de nuevo a esa estrecha relación entre sexualidad femenina y espiritualidad.

"El simbolismo sexual y ginecológico de las conchas marinas y de las ostras implica [...] una significación espiritual: el "segundo nacimiento", realizado mediante la iniciación, es posible gracias a la misma fuente perenne que sostiene la vida cósmica. De aquí también la misión de las conchas y de las perlas en los usos funerarios; el difunto no se separa de la fuerza cósmica que ha alimentado y regido su vida" (Eliade, 1992: 145).

De nuevo la figura de la diosa reaparece a través de este nuevo elemento -la concha ${ }^{26}$ puesto que varias son las deidades femeninas que aparecen con ella como uno de sus atributos principales, vistiendo su cuerpo o a modo de ornamento. Tal es el caso de Afrodita, las nixes, Laksmi o diosas pertenecientes a la santería cubana como Yemanjá ${ }^{27}$ entre otras. La conexión de la diosa y el elemento del agua de nuevo muestra un carácter dual puesto que no sólo es considerada como la Gran Madre dadora de vida de la que surge todo, sino que también se le atribuye un carácter negativo. Esa relación de lo femenino con la oscuridad y el pecado ha sido construida con el paso del tiempo y sobre todo, debido a la instauración del patriarcado y de las grandes religiones monoteístas que han sustituido a las diosas por deidades masculinas además de modificar ciertas de sus cualidades resaltando mayoritariamente su lado tenebroso, peligroso o malvado. El agua está presente en muchos rituales de purificación y es considerada como nutricia y como principio del que surge la vida según muchas teorías, mitos y tradiciones, pero también está en ocasiones vinculada con el mal, sobre todo en aquellos casos en los que se alude a las aguas profundas y oscuras donde habitan seres malignos. Pero el agua clara y cristalina nos permite también observar nuestro reflejo percatándonos de nuestra dualidad y reflexionando así sobre ese binomio vida-muerte propio no sólo del elemento que nos ocupa, sino de la mujer en sí -recuérdese cómo también el espejo forma parte de los objetos que conforman el santuario donde se ubica la Madonna de Crossbones (fig. 8)-. Por ello, en las aguas y en todos aquellos personajes femeninos asociados con éstas encontraremos una clara vinculación con la fuente de vida, pero

\footnotetext{
26 "Entre los griegos, la perla era el emblema del amor y del matrimonio [...]. En Chipre se consagraban conchas a Afrodita; la diosa había sido conducida allí después de su nacimiento de la espuma del mar [...]. En Siria, la diosa se llama "Señora de las Perlas"; en Antioquía, Margariô [...]. El nacimiento de Afrodita en una concha ilustraba este lazo místico entre la diosa y su principio. Este simbolismo del nacimiento y de la regeneración era lo que inspiraba la función ritual de las conchas [...]. Gracias a su poder creador -en tanto que emblemas de la matriz universal-, las conchas tienen su lugar en los ritos funerarios" (Eliade, 1992: 141, 142).

27 "Entre las entidades femeninas, la que ocupa el primer lugar [en la santería cubana] es Yemanjá, cuyo nombre africano, Yé-omo-ejá, significa "madre de los peces pequeños". En su origen, era una diosa de las aguas dulces, ligada a un río, [...]. En Brasil se transformó en diosa suprema del mar y hoy es la más conocida de los orixá yorubanos [...]. Es la figura maternal por excelencia, a la vez sensual y seria, independiente y generosa, enérgica y posesiva" (Marcos, 2004: 304).
} 
también con la muerte. Mares, océanos, lagos y ríos son habitados por seres que permiten la creación y la germinación, pero también por otros que nos atrapan con sus encantos conduciéndonos a una oscuridad de la que nunca nos dejarán escapar.

Crossbones se convierte así en una llamada al despertar de la conciencia femenina, invitando a vivir de forma activa la espiritualidad y la sexualidad de la mujer. A pesar de que muchos de los participantes en las ceremonias y en la conservación del lugar sean hombres, la energía femenina está del todo presente no sólo a través de los rituales que se celebran en las inmediaciones del jardín, sino mediante los elementos que se pueden visualizar en el interior y las ofrendas que los y las participantes depositan en sus verjas.

\section{Conclusiones}

Crossbones Graveyard ha pasado de ser un espacio al que se ha querido proteger para mantener la memoria de las "Winchester Geese" a un enclave donde no sólo se recuerda quiénes eran además de conservar y difundir esa parte de la historia que permanecía escondida bajo las sombras del Bankside más oscuro. Crossbones Graveyard se ha convertido en un verdadero santuario donde se rinde además culto a la espiritualidad y sexualidad femenina recordando incluso el papel de la Diosa dándole una mayor visibilidad y protagonismo entre la práctica de las religiones monoteístas que la dejan relegada a un segundo plano. Se toma conciencia de una realidad olvidada, de la parte femenina más primitiva y salvaje que se encuentra retenida por miedo a las normas preestablecidas de la sociedad. Se pasa de la teoría a la práctica viviendo por completo lo que allí se reivindica realizando acciones de forma grupal que enriquecen el lugar.

Las "Winchester Geese" pasan así de ser infravaloradas y repudiadas a conmemoradas y valoradas recordando que la lucha por los derechos de la mujer aún sigue en pie. Acciones como las desarrolladas entorno a Crossbones consiguen que historias protagonizadas por mujeres que han caído en el olvido vuelvan a resurgir de entre sus cenizas dándose a conocer y visibilizando el papel de la mujer en la historia.

Rompiendo las barreras de la religión, la raza o el género quienes colaboran en este movimiento consiguen borrar de su mente, aunque sea por un instante, todos los estereotipos y normas preestablecidas por la sociedad dejándose llevar por sus rituales invadidos por el pecado, la magia y la hechicería. Nos encontramos ante un nuevo movimiento feminista que cada vez tiene una mayor presencia y, aunque no sea fácilmente aceptado, sus resultados son los esperados teniendo un gran poder de difusión y consecuentemente de concienciación. La diversidad y la libertad son dos de sus grandes pilares haciendo así posible una amplia participación que genera un enriquecimiento y una retroalimentación constante. 


\section{BIBLIOGRAFÍA}

- Bernárdez, Enrique (2002): Los mitos germánicos. Madrid: Alianza Editorial.

- Blavatsky, Helena P. (2000): La Doctrina Secreta. Simbolismo Arcaico Universal. Síntesis de la Ciencia, la Religión y la Filosofía. $2^{\text {a }}$ edición. Málaga: Editorial Sirio. Tomo II.

- BOST - Bankside Open Spaces Trust (2015a): "Crossbones Garden Information Pack". Disponible en: http://www.bost.org.uk/wp-content/uploads/Crossbones-Garden-the-packMarch.pdf [16/01/2017].

. (2015b): “A new open space for SE1. Crossbones Garden. Information Pack". Disponible en: http://www.bost.org.uk/wp-content/uploads/Crossbones-Garden-the-packMarch1.pdf [16/01/2017].

. (2016): "The gradual greening of Bankside. Interview with Tim Wood, chair of Bankside Open Spaces". Disponible en: http://www.bost.org.uk/wpcontent/uploads/2014/04/2016-01-22-Tim-Wood-interview-BOST-history1.pdf [18/01/2017].

- Brandon, David y Brooke, Alan (2011): Bankside. London's original district of sin. Great Britain: Amberley.

- Crossbones Fanzine Web (2012): “Crossbones acts". Disponible en: http://www.publicworksgroup.net/2012/11/05/120805_crossbones_fanzine_web.pdf [19/01/2017]

- Chevalier, Jean y Gheerbrant Alain (2007): Diccionario de los símbolos. Barcelona: Herder editorial.

- Eliade, Mircea (1955): Imágenes y símbolos. Madrid: Taurus Ediciones.

- May, Pedro Pablo G. (2000): Mitos nórdicos. Madrid: Editorial Acento.

- Golden, Grace (1951): Old Bankside. London: Williams \& Norgate LTD.

- Gombrich, Ernst H. (1992): Aby Warburg. Una biografía intelectual. Madrid: Alianza Editorial.

- Harris, Adrian (2010): "Honouring The Outcast Dead: The Cross Bones Graveyard". En: Interfaith \& Social Change: Engagements from the Margins conference. Winchester: Winchester University. Disponible en: http://www.thegreenfuse.org/papers/Cross_Bones/Cross_Bones.pdf [18/01/2017].

- Marcos, Sylvia (2004) (ed.): Religión y Género. Madrid: Editorial Trotta.

- Noble, Vicki (2004): La mujer Shakti. Sintiendo nuestro fuego, sanando nuestro mundo. El nuevo chamanismo femenino. Madrid: Perito en Lunas.

- Página Oficial Crossbones (n.d.): “Crossbones”. Disponible en: http://crossbones.org.uk [20/01/2017].

- Panofsky, Erwin (1979): El significado en las artes visuales. Madrid: Alianza editorial. (1985): La perspectiva como "forma simbólica". 5 a edición. Barcelona: Tusquets 
Editores.

. (1989): Idea. Ensayos Arte Catedra. $7^{\mathrm{a}}$ edición. Madrid: Ediciones Cátedra.

(1994): Estudios sobre iconología. Madrid: Alianza Editorial.

- Pérez Asperilla, Estíbaliz (2013): Björk: la revolución de la diosa. Tesis doctoral dirigida por Pilar Aumente Rivas. Madrid: Universidad Complutense de Madrid.

. (2016): "Los cinco sentidos en el Distrito Cultural: aplicación del Atlas Multisensorial en Bankside". En Miguel Ángel Chaves Martín y Jesús-Pedro Lorente (eds.): Barrios Artísticos y Distritos Culturales. Nuevos espacios para la creatividad y la revitalización urbana. Madrid: Icono 14 Editorial. Colabora MINECO Plan Nacional de I+D+i, pp. 229-252.

- Reilly, Leonard y Marshall, Geoff (2001): The story of Bankside. From the River Thames to St. George's Circus. Londres: London Borough of Southwark.

- Rendle, William (1878): Old Southwark and its people. London: W. Drewett.

- Roberts, Howard y Godfrey, Walter H. (1950): Survey of London. Volumen XXII: Bankside (the parishes of St. Saviour and Christchurch Southwark). Londres: London County Council.

- Rodríguez, Pepe (1999): Dios nació mujer. Barcelona: Ediciones B.

- Schleberger, Eckard (2004): Los dioses de la India. Forma, expresión y símbolo. Diccionario temático de iconografía hinduista. Madrid: Abada Editores.

- Slade, Paul (2013): The Outcast Dead. London: planetslade.com. Versión [online] Disponible en: http://www.planetslade.com/pdf/crossbones.pdf [16/01/2017].

- Starhawk y Valentine, Hilary (2001): El aprendizaje de una maga. Los doce cisnes salvajes. Madrid: Edaf.

- Starhawk (2002): La Danza en Espiral. Un Amor Infinito. El renacimiento de la antigua religión de la Gran Diosa. Barcelona: Ediciones Obelisco.

- Steph Berns (2016): "In Defense of the Dead: Materializing a Garden of Remembrance in South London”. En: Material Religion. The Journal of Objetcts, Art and Belief, vol. 12, nº 2 , pp. 165-188. Versión [online] Disponible en: http://www.tandfonline.com/doi/pdf/10.1080/17432200.2016.1172762 [18/01/2017].

- Warburg, Aby (2005): El renacimiento del paganismo. Aportaciones a la historia cultural del Renacimiento europeo. Madrid: Alizanza editorial. . (2010): Atlas Mnemosyne. Madrid: Ediciones Akal. 